\title{
Atelosteogenesis type III
}

INSERM

\section{Source}

INSERM. (1999). Orphanet: an online rare disease and orphan drug data base. Atelosteogenesis type III. ORPHA:56305

Atelosteogenesis III (AOIII) is a skeletal dysplasia characterized by short limbs dysmorphic facies and diagnostic radiographic findings. 